\title{
Recycling and Reuse of Wastewater Generated in Car-Washing Facilities
}

\author{
Elgaali Elgaali*, Majid Akram
}

Civil Engineering Program, Higher Colleges of Technology, Dubai Men's College, Dubai, 337150, UAE

\begin{tabular}{l} 
A R T I C L E I N F O \\
\hline Article history: \\
Received: 23 December, 2020 \\
Accepted: 08 March, 2021 \\
Online: 17 March, 2021 \\
\hline
\end{tabular}

Keywords:

Sustainability

Wastewater

Recycling

\begin{abstract}
A B S T R A C T
Fresh water is already scarce in the world, especially in the Middle East (ME). Desalination industry is the main supplier of the potable water to the municipalities in the ME region. It is well known the high cost of a liter of water produced by the desalination process. Unfortunately, car-washing service consumes substantial amount of this desalinated water. This paper describes a filtration system designed and tested for treatment and reuse of the wastewater generated in car-washing stations. The filtration system assembled from two filters: (1) sand and gravel mix, and (2) activated carbon. The paper is an extension of work originally presented in ASET conference in Dubai. The quality of the effluent (treated wastewater) was investigated and determined in Dubai central laboratories. Wastewater samples were grabbed from different car service stations. Representative samples were prepared and the concentrations of the following parameters were measured in each sample of the effluent: (1) Biological oxygen demand (BOD), (2) Chemical oxygen demand (COD), (3) Total dissolved solids (TDS), (4) Total suspended solids (TSS), and (5) Oil and grease $(O G)$. The results show that the filter system removes the BOD and COD at an efficiency as high as $97.5 \%$, the TSS at $90 \%$, and the TDS and OG at $85.5 \%$. In general, the quality of the effluent was found to fall within the standards set by Dubai regulatory authorities. Further research is recommended to enhance the filtration system performance and make it commercially applicable.
\end{abstract}

\section{Introduction}

Water is also termed as white gold in the age of its scarcity and increasing population in the world. The dynamics of geopolitics is changing based on the sharing of this valuable resource among different countries, especially in the Middle East. Desalination industry is the main supplier of the fresh water to the municipalities in the United Arab Emirates (UAE). It is well known the high cost of a liter of water produced by the desalination process (\$2.0 / gallon) [1], [2]. Besides, desalination process adversely affects the marine environments. For example, brine as a by-product of the desalination process is usually discharged back into the sea degrading the sea water quality and posing hazards to the marine fauna and flora [3]. This makes the water produced from desalination a precious commodity. Unfortunately, considerable amount of the desalinated water produced, is used for non-potable uses (e.g. car-washing) putting more stress on already stressed fresh water resources. Therefore,

\footnotetext{
* Corresponding Author: Elgaali, P.O.Box: 15825, Dubai, UAE, 971552493085,
} eelgaali@hct.ac.ae considerable amount of research has been directed towards exploring methods and techniques to recycle and reuse the wastewater to augment the high fresh water consumption especially for non-potable uses [4].

Globally, wastewater recycling/reuse has been practiced for a while for different purposes. Wastewater, is mainly recycled to minimize the disposed amount in order to alleviate the impacts on environment (degradation and pollution). Recently, it has been used as a lower cost alternative for fresh water in non-potable practices. Ground water recharging one of the first applications has been practiced. Other applications include irrigation of green landscape, air cooling (chillers), and recently toilet flushing [5]. In this region (Middle East), wastewater recycling and reuse is widely used to sustain the valuable and expensive water produced from the desalination of sea water [6]. For example, Dubai municipality recycles and reuses the wastewater for irrigation of the green areas in the landscape of the city [7]. Table 1 shows some standards set for the recycled water to be reused for irrigation. 
Table 1: Standards of water recycled for irrigation

\begin{tabular}{|l|l|c|c|}
\hline Symbol & Unit & $\begin{array}{c}\text { Maximum Limit } \\
\text { for Unrestricted } \\
\text { Irrigation }\end{array}$ & $\begin{array}{c}\text { Maximum Limit } \\
\text { for Restricted } \\
\text { Irrigation }\end{array}$ \\
\hline BOD & $\mathrm{mg} / \mathrm{L}$ & 200 & 200 \\
\hline COD & $\mathrm{mg} / \mathrm{L}$ & 200 & 200 \\
\hline TDS & $\mathrm{mg} / \mathrm{L}$ & 2000 & 2000 \\
\hline TSS & $\mathrm{mg} / \mathrm{L}$ & 15 & 30 \\
\hline $\mathrm{pH}$ & $\mathrm{mg} / \mathrm{L}$ & $6-8$ & $6-8$ \\
\hline
\end{tabular}

Source: Dubai municipality

The practice of car-washing is mounting in this region (ME, UAE). The harsh dusty weather necessitates the extension of this practice especially in the UAE. Unfortunately, car-washing service consumes substantial amount of the desalinated water produced in the emirate of Dubai [2]. The car-washing activity is estimated to consume around 30 gallons to wash small size car, and around 60 gallons to wash big size car. A published survey, extracted from 59 car-washing stations, shows that the water consumption reaches $378770 \mathrm{~m}^{3}$ per year [2]. This amount represents around $0.2 \%$ of the total annual production.

Currently, the whole amount of water wasted in car-washing facilities, is usually discharged into the city sewer systems after brief in situ pretreatment in holding tanks to facilitate settling of large solid particles. In general, the car-washing facilities pay relatively high cost to dispose their wastewater in the municipal sewer system burdening the car-washing facilities with more operational cost. The estimated costs of water usage and disposal for each car-washing facility are $\$ 37000$ and $\$ 4000$ respectively [2]. Therefore, considerable amount of research has been directed towards exploring methods and techniques to recycle and reuse the wastewater from car-washing to augment the high consumption of fresh water and reduce the operational cost [8] [12].

Wide range of technologies, from simple to very complex, are widely used now to treat and recycle the wastewater. For example, the membrane filters (reverse osmosis (RO), micro, ultra, and Nano-filtration) are widely used to remove the dissolved solids (DS) and particulate matter (PM); the membrane bioreactor (MBR) systems are increasingly used now as an efficient technique to reclaim wastewater; the oxidation technique which is advanced to combine ozone, ultraviolet (UV) light, and hydrogen peroxide to create the highly reactive hydroxyl radical (.OH) [4]. The use and level of treatment required, dictates the cost of water recycling [4], [13]-[17].

Almost, all the current treatment methods incur high initial and operational costs. Therefore, this research is a genuine effort to develop and test a system to treat, recycle, and reuse the wastewater generated in car washing facilities in situ. The proposed system incur low initial and operational costs. The proposed system can be well described as a simple filter designed and assembled from natural materials from local sources. The system is assembled from two filter: (1) sand and gravel mix, and (2) activated carbon. For the purpose of this study, the quality of the effluent (treated wastewater) was investigated and determined in Dubai central laboratories. Wastewater samples were grabbed from different car service stations. Representative samples were prepared and the concentrations of the following parameters were measured in each sample of the effluent: (1) Biological oxygen demand (BOD), (2) Chemical oxygen demand (COD), (3) Total dissolved solids (TDS), (4) Total suspended solids (TSS), and (5) Oil and grease (OG), (6) $\mathrm{pH}$. The results are presented and discussed in section 3 of this paper.

\section{Materials and Methods}

The test program, in this research, is developed to filter and examine the quality of raw and treated wastewater samples.

\subsection{Water Samples}

The amount of the wastewater tested in this study was collected from 8 stations of car service around Dubai, UAE. Composite sampling was adopted. Composite sampling is widely used to monitor wastewater discharges [15]. In order to collect representative samples, several samples were grabbed throughout the car's washing process. Figure 1 shows the samples collection process. The samples then were thoroughly mixed together into a composite sample (Figure 2). The characteristics of the composite sample (raw wastewater) are presented in Table 2.

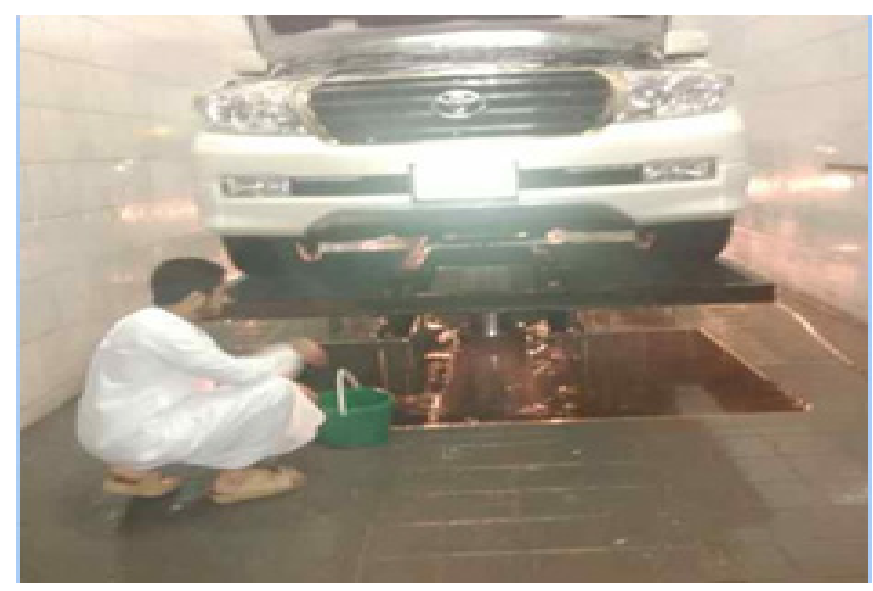

Figure 1: Samples collection process

The samples were screened first to remove the large particles or grit that might damage the filter and then passed through the two stage filter.

Table 2: Raw Wastewater Characteristics

\begin{tabular}{|l|c|}
\hline Parameter & $\mathrm{mg} / \mathrm{L}$ \\
\hline Biological oxygen demand (BOD) & 235 \\
\hline Chemical oxygen demand (COD) & 976 \\
\hline Oil and grease & 88 \\
\hline PH value at $25^{\circ} \mathrm{C}$ & 7.2 \\
\hline Total dissolved solids (TDS) & 1100 \\
\hline
\end{tabular}




\begin{tabular}{|l|c|}
\hline Total suspended solids (TSS) & 112 \\
\hline Cadmium & 0.08 \\
\hline Chromium & 0.5 \\
\hline Copper & 0.38 \\
\hline Lead & 0.53 \\
\hline Nickel & 0.2 \\
\hline Zinc & 1.98 \\
\hline
\end{tabular}

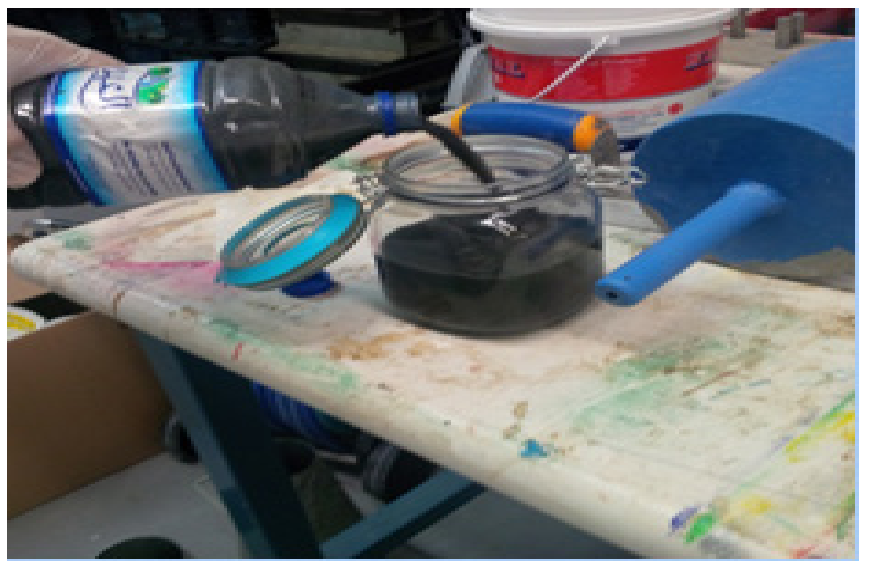

Figure 2: Sample of raw wastewater

\subsection{Filter Fabrication}

In order to increase the effectiveness of treatment, two filters were assembled and used. The two filter units were fabricated and assembled at the civil engineering workshop in the Dubai men's campus-higher colleges of technology. The two-stage filter was fabricated using materials available from the local market. These materials include: (1) Coarse Gravel, (2) Fine Gravel, (3) Sand, and (4) Activated Carbon. The schematic and the assembly of the two-stage filter are shown in Figure 3-a and 3-b respectively. For better depiction, the unit of the sand and gravel is magnified in the right part of Figure 3-b.

The schematic diagram shown in Figure 3-a, depicts the filtration process. From the entrance (inlet) the water flows through the first stage filter (dual media of sand and gravel) and then through the second stage filter (activated carbon) towards the exit point (outlet). Throughout the filtration process, samples of treated water were at outflow-1 and outflow-2 (Figure 3-a). Since Dubai regulatory authorities stipulate strict standards for the use of recycled water for different beneficial activities, the quality of the treated water was verified in the laboratories of Dubai municipality.

For better illustration of the effectiveness of the filter and the filtration process, the characteristics of the treated water samples were compared to the characteristics of the raw wastewater (baseline). The effectiveness of the filter is further indicated by the removal efficiency which is estimated by a formula taking the following form:

$$
R \%=\left(C_{i n}-C_{\text {out }}\right) / C_{\text {in }}
$$

where $\mathrm{R} \%$ is the removal efficiency, $\mathrm{C}_{\text {in }}$ is the initial concentration of the parameter in the influent (raw water), $\mathrm{C}_{\text {out }}$ is the final concentration of the parameter in the effluent (treated water).

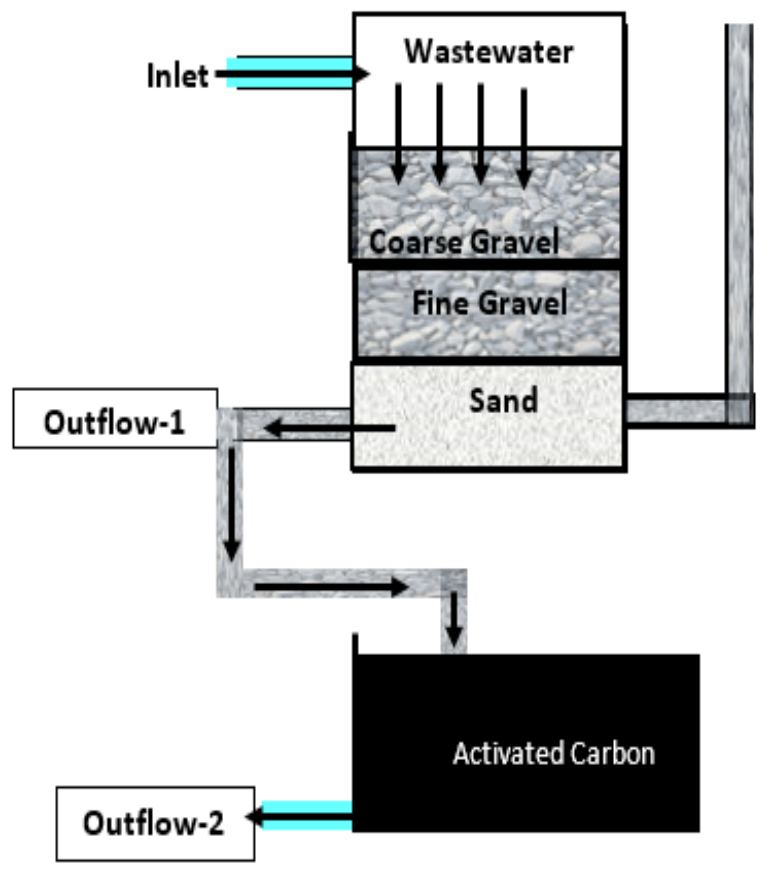

(a)

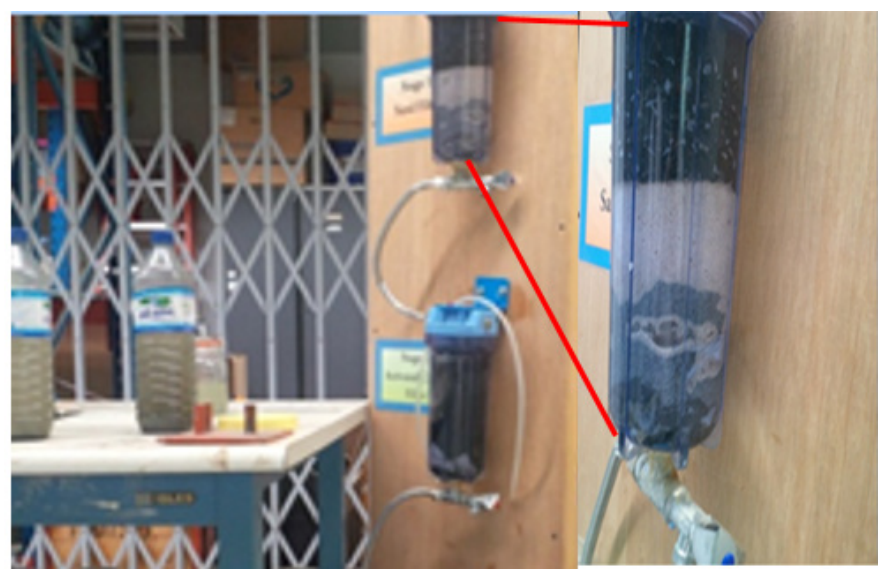

(b)

Figure 3: Schematic and assembly of the two-stage filter-workshop-higher colleges of technology-Dubai men's campus

\section{Results and Discussion}

The results of the lab analysis of the raw and treated water samples are presented in Tables 3. The concentrations of the quality parameters in the treated water are depicted and compared to the levels of the parameters in the raw wastewater (baseline). Then the removal efficiency of the designed filter is estimated.

BOD removal: as shown in the table the $\mathrm{BOD}$, as indicator of the strength of the organic pollution in the water sample, is reduced from 235 to $33.8 \mathrm{mg} / \mathrm{L}$ with removal efficiency reaches $86 \%$. The huge reduction in the BOD is mainly attributed to the type of sand used in stage1 filter.

COD removal: the COD, as indicator of the strength of the organic pollution in the water sample, is also experienced huge reduction from 976 to $193 \mathrm{mg} / \mathrm{L}$ with removal efficiency reaches $81 \%$.

TDS removal: it is well known that the high level of the total dissolved solids (TDS) can result in many problems such as scale 
deposit and precipitates on fixtures; corrosion of fixtures, and reduction or malfunctioning of the filter and associated equipment [18]. Successfully, at this stage the level of reduction of the total dissolved solids (TDS) is fairly good (from $1100 \mathrm{mg} / \mathrm{L}$ to 249.6 $\mathrm{mg} / \mathrm{L}$ ) with removal efficiency reaches $78 \%$.

TSS removal: accumulation of TSS in water systems usually causes blockage of the systems and damages the nozzles widely used in car washing facilities. Moreover, by time TSS create a good medium for bacterial growth which pose potential health risks. Unfortunately, the reduction in the total suspended solids (TSS) is of less magnitude of $57 \mathrm{mg} / \mathrm{L}$ (from 112 to $55 \mathrm{mg} / \mathrm{L}$ ) with removal efficiency reaches $51 \%$.

OG removal: To avoid any blockage to the filter/reuse systems oil and grease $(\mathrm{OG})$ was a parameter of great interest in this research. Effectively, the level of the OG was reduced from 88 to $12 \mathrm{mg} / \mathrm{L}$ with removal efficiency reaches $88 \%$.

In general, at this stage the performance of the filter, as measured by the removal efficiency, was fairly good. The removal efficiency was as high as $85 \%$ for BOD and as low as $50 \%$ for TSS, with average overall average removal efficiency of $73.51 \%$.

The following results can be extracted from Table 3 after stage2:

BOD, the removal efficiency of the BOD improved by magnitude of $8 \%$ (from $85.6 \%$ to $93.32 \%$ );

COD, the removal efficiency of the COD improved by magnitude of $18 \%$ (from $80.23 \%$ to $98.5 \%$ );

TDS, the removal efficiency of the TDS improved by magnitude of $8 \%$ (from $77.31 \%$ to $85.31 \%$ );

TSS, the removal efficiency of the TSS improved by magnitude of $39 \%$ (from $50.90 \%$ to $90.0 \%$ );

OG, the removal efficiency of the OG stayed the same at $86 \%$.

In general, the removal efficiency was as high as $97 \%$ for BOD and as low as $85 \%$ for TDS, with average overall average removal efficiency of $93 \%$. It is very clear from the results that adding the activated carbon component to the filter assembly enhanced the filter performance a lot. However, within the limits of the parameters (BOD, COD, TDS, TSS, and OG) in the wastewater, it appears that the current levels of TDS had little effect on the removal of parameters examined in this study [18]. However, relative to other studies, the filter system developed, proved to be very effective in producing treated water of high quality and could be reused for car washing safely [8] - [12].

Table 3: Characteristics of raw and treated wastewater

\begin{tabular}{|c|c|c|c|c|c|}
\hline \multirow{2}{*}{ Parameter } & \multicolumn{3}{|c|}{ Pollution Level } & \multicolumn{2}{c|}{$\begin{array}{c}\text { Removal } \\
\text { efficiency }\end{array}$} \\
\cline { 2 - 6 } & Original & Stage1 & Stage2 & Stage1 & Stage2 \\
\cline { 2 - 6 } & $\mathrm{mg} / \mathrm{L}$ & $\mathrm{mg} / \mathrm{L}$ & $\mathrm{mg} / \mathrm{L}$ & $\%$ & $\%$ \\
\hline \multirow{2}{*}{ BOD } & 235 & 33.85 & $<7$ & 85.6 & 97.32 \\
\hline COD & 976 & 193 & 15 & 80.23 & 98.5 \\
\hline OG & 88 & $<12$ & $<12$ & 86.36 & 86.36 \\
\hline TDS & 1100 & 249.6 & 161.6 & 77.31 & 85.31 \\
\hline TSS & 112 & 55 & $<11$ & 50.9 & 90 \\
\hline
\end{tabular}

Figure 4-a, illustrates the high performance of stage 1 of the filter. The color of the sample shown, is greatly diluted from dark black to grey one. This indicates the high removal of the total suspended solid (TSS). Figure 4-b shows from right to left samples of raw wastewater, water after stage 1 , and after stage 2 .

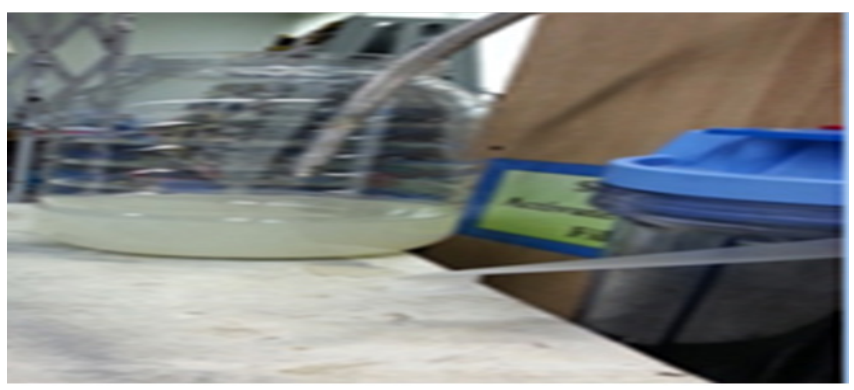

(a)

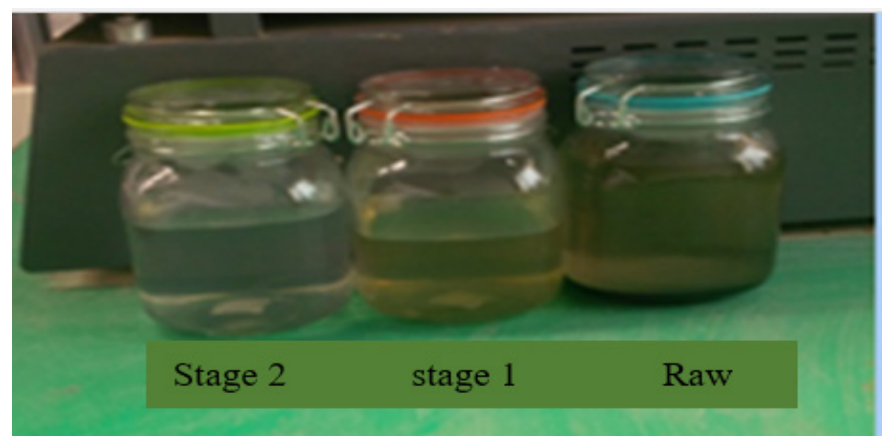

(b)

Figure 4: Raw and treated water samples-environmental laboratory-higher colleges of technology-Dubai men's campus

Figure 5 clearly depicts the removal efficiency of the filter system in magnitude $(\mathrm{mg} / \mathrm{L})$ and percentage.

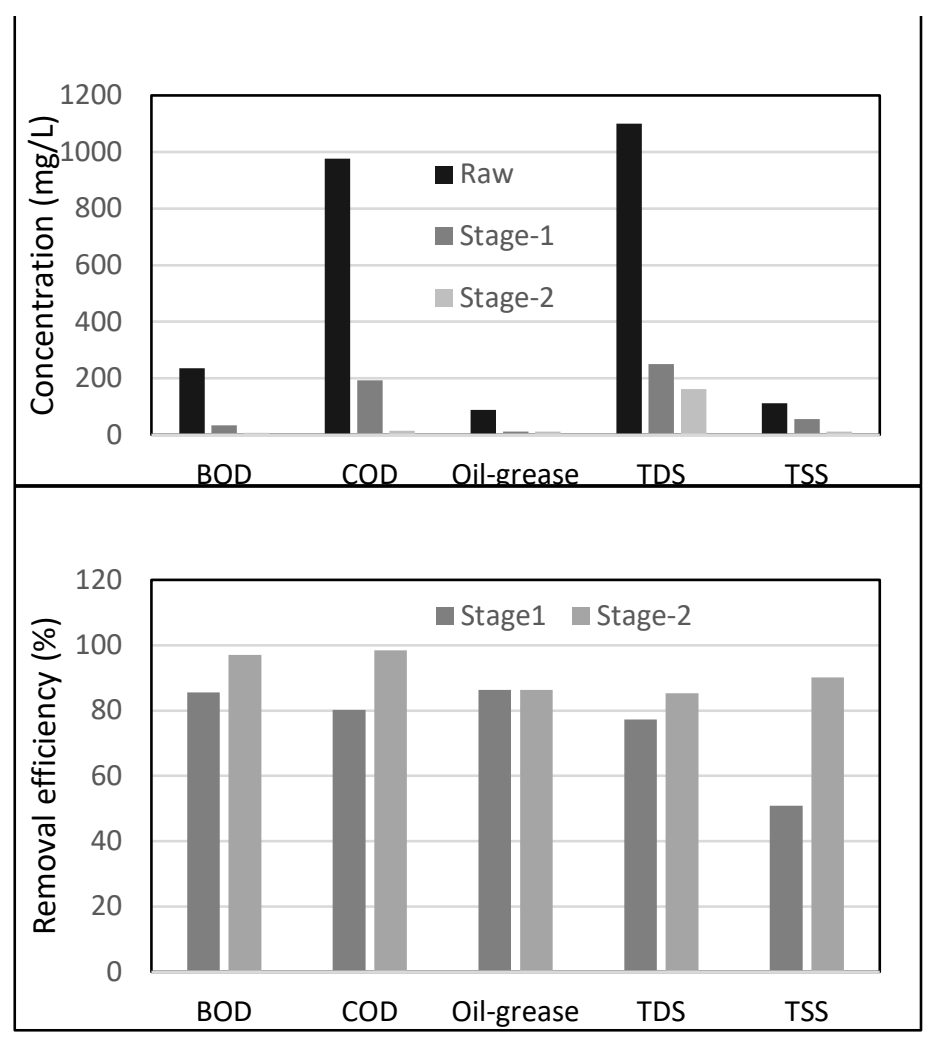

Figure 5: Removal efficiency in magnitude and percentage 


\section{Summary and Conclusions}

This paper describes a filtration system designed and tested for treatment and reuse of the wastewater generated in the car's service stations. The filtration system assembled from two filters: (1) sand and gravel mix, and (2) activated carbon. The system is made of natural materials from local sources. The system is anticipated to incur low initial and operational costs. The quality of the effluent (treated wastewater) was investigated and determined in Dubai central laboratories. Wastewater samples were grabbed from different car service stations. Representative samples were prepared and the concentrations of the following parameters were measured in each sample of the effluent: (1) Biological oxygen demand (BOD), (2) Chemical oxygen demand (COD), (3) Total dissolved solids (TDS), (4) Total suspended solids (TSS), and (5) Oil and grease (OG). The results are presented, discussed, and documented through several figures and table and the following conclusions were drawn:

According to the results, the removal efficiency of the BOD, COD, TDS, TSS, and OG is of magnitudes of 97.32, 98.50, 85.s1, 90.0 , and $86.36 \%$ respectively. The results suggest that, under the range of the current levels of the parameters investigated the performance of the system was good.

Very clear, adding the activated carbon component to the filter assembly led to a great enhancement in the removal efficiency of the filtration process. However, this cannot be said about the TDS removal. The removal efficiency of the TDS, unlike the other parameters, did not change from stage1 to stage2. This result indicates that activated carbon is not that efficient in filtering out the TDS. Alternative material (e.g. silt) must be sought and tested to improve the removal efficiency of the TDS. However, it can be concluded that the results show that the filter system achieved high performance in removing the parameters tested. In general, the quality of the effluent was found to fall within the standards set by Dubai regulatory authorities (Table 1).

Further research is recommended to enhance the filtration system performance and make it commercially applicable. Significant savings can be realized from treating and reusing of the wastewater generated in the car service stations. For example, sustaining (saving) precious resource (desalinated water) for the future and reducing the carbon foot-print on the planet earth.

\section{Conflict of Interest}

No conflict of interest in publishing this paper.

\section{Acknowledgment}

The authors would like acknowledge the contribution of Dubai Men's College (DMC) - Higher Colleges of technology, and the following students: Mr. Fahad Yusuf and Mr. Abdulla Salem.

\section{References}

[1] M. Akram and E. Elgaali, "Recycling of wastewater from car-washing facilities for landscaping applications," Advances in Science and Engineering Technology International Conferences (ASET), Dubai, United Arab Emirates, 1- 4, 2019, doi: 10.1109/ICASET.2019.8714351.
[2] Dubai Electricity and Water Authority (DEWA), Sustainability Report, 2018, http://www.dewa.gov.ae.

[3] N. Kress, Y. Gertner, E. Shoham-Frider, "Seawater quality at the brine discharge site from two mega size seawater reverse osmosis desalination plants in Israel (Eastern Mediterranean)," Water Research, 171, 115402, 2020, doi.org/10.1016/j.watres.2019.115402.

[4] E. Mohamed, E. Elgaali, "Sustainable concrete made of construction and demolition wastes using recycled wastewater in the UAE" Journal of Advanced Concrete Technology-Japan, 10, 110-125, 2012, doi: 10.3151/ jact. 10.110 .

[5] Hunter Water Corporation, Annual Report, 2019, https://www.hunterwater .com. au/our-water/sustainability/recycling-and-reuse.

[6] Appropedia organization, sustainability report, water recycling, 2019, http://www.appropedia.org/Water_recycling

[7] Dubai municipality-waste department, Annual Report, 2019, https://www.dm.gov.ae/municipality-business/environment-andcoasts/waste-department.

[8] M. Sarmadi, F. Maryam, H. Saleh, "Efficient technologies for carwash wastewater treatment: a systematic review," Environmental Science and Pollution Research, 27(28), 2020, doi.10.1007/s11356-020-09741-w.

[9] A. Oghenekome, O. Ovie, "Management of wastewater from car wash sites using locally sourced natural coagulants and simple filtration Process," International Journal of Scientific and Research Publications, 10(12), 621625, 2020, DOI: 10.29322/IJSRP.10.12.2020.p10872.

[10] M. Emamjomeha, H. Jamalia, Z. Naghdalib, M. Mousazadeha, "Carwash wastewater treatment by the application of an environmentally friendly hybrid system: an experimental design approach," Desalination and Water Treatment, 160, 171-177, 2019, DOI:10.5004/dwt.2019.24382.

[11] R. Zaneti, R. Etchepare, J. Rubio, "Car wash wastewater treatment and water reuse - A case study," Water Science \& Technology, 67(1), 82-89, 2013, DOI: $10.2166 /$ wst.2012.492

[12] J. Rubio, R. Zaneti, "Treatment of washrack wastewater with water recycling by advanced flocculation-column flotation," Desalination and Water Treatment, 8, 146-153, 2009, DOI: 10.5004/dwt.2009.679.

[13] M. J. Hammer Sr., M. J. Hammer Jr., Water and Wastewater Technology, Prentice Hall, 2003, ISBN: 0131911406.

[14] S. Judd, The MBR Book: Principles of Membrane Bioreactors in Water and Wastewater Treatment, Elsevier, UK, 2011.

[15] R. O. Gilbert, Statistical Methods for Environmental Pollution Monitoring, John Wiley, 1987, ISBN: 0471288780.

[16] L. Chen, F. Ling, G. Bakker, W. T. Liue, G. Medemaa, W. Meer, G. Liuab, "Assessing the transition effects in a drinking water distribution system caused by changing supply water quality: an indirect approach by characterizing suspended solids," Water Research, 168, 115159, 2020, doi: 10.1016/j.watres.2019.115159

[17] I. Husain, M. Alkhatib, M. Jammi, M. Mirghani, Z. Zainudin, A. Hoda, "Problems, control, and treatment of fat, oil, and grease (FOG): a review," J. Oleo Sci., 63(8), 747-752, 2014, doi: 10.5650/jos.ess 13182.

[18] X. Sarah, M. Jason, "Study on the effect of total dissolved solids (TDS) on the performance of an SBR for COD and nutrients removal' Journal of Environmental Science and Health, Toxic/Hazardous Substances and Environmental Engineering. 53(2), 146 -153, 2017, https://doi.org/10.1080/ 10934529.2017.1383130. 